\title{
Assessment of Public Lavatories in Akure, Nigeria
}

\author{
Dr. Olukayode Rotowa* \\ Department of Urban and Regional Planning, Federal University of Technology, Akure, Ondo State, Nigeria \\ *Corresponding Author: Dr. Olukayode Rotowa, Department of Urban and Regional Planning, Federal \\ University of Technology, Akure, Ondo State, Nigeria
}

\begin{abstract}
Human waste as a product of metabolic activity is a source of environmental pollution. Public toilets in Akure are a necessity which in most cases is not incorporated into the urban plan of cities in developing countries. It became a necessity due to the rapid urbanization and the need to care for the migrant population. The study focuses on the condition and the patronage of the public toilet in Akure. Using the purposive sampling technique, 100 respondents were interviewed in the study. The results showed that the number of public toilets was inadequate for the population of the city. The toilets were not managed properly while the facilities were not properly maintained. It is therefore recommended that more toilets be built by non-governmental organizations. This is the fact that most of the toilets were built by the World Bank. A general awareness on location and facilities available should be created for people travelling through Akure. Other public places should be provided with the facility in order to reduce open defecation.
\end{abstract}

Keywords: Public Toilet, World Bank, Excreta, Urine, open defecation

\section{INTRODUCTION}

Globally, at least 2.6 billion people lack access to improved sanitation, and 437 million ofthem live in sub-Saharan Africa (WHO, 2004, Niwagba, 2007). It is equally estimated that about 1 billion people still defecate in the open. When people lived in small groups as hunters and gatherers, environment naturally decomposes their refuse and human wastes. Waste disposal became an important concern as societies moved from nomadic cultures to concentrate settlements. This is because of the low carrying capacity of the environment to handle it. Safe and hygienic disposal of human wastes is an increasing problem in most cities in Nigeria, as it is in most developing countries. Improper, unsafe and unhygienic disposal of human excreta has a direct relation to environmental quality (Pathak, 1991). Leading to high mortality, morbidity and decreasing community health, sanitation and productivity. The combined effects of rural-urban migration and congregation of urban poor have led to overstretching of water and sanitation facilities. The local government, which is saddled with the oversight on sanitation is not financially sustained and is bedeviled with resource constraint, leading to rapid deterioration in quality of life and community health. The situation will be further aggravated if urgent steps are not put in place to improve sanitation through people's participation, inter-sectoral co-ordination, innovative and appropriate technology for the management of human waste.

A public toilet is a toilet that is accessible to the general public (Drewko, 2007). Two types of public toilets have been identified by Drewko (2007). These are the community or shared toilet and public sanitation facility. The former is a toilet provided in overcrowded settlements, where residents do not own private sanitation facility. Hence, it serves a role of facility shared among residents. The latter, is a toilet accessed by many people in transit, available at railway stations, bus stops, markets, shopping areas, parking lots, entertainment events, etc... They are normally used by people not necessarily resident in the vicinity of the toilet, but are passing by (Drewko, 2007).The need to urinate and defecate is irrepressible, hence, when public toilets are not provided, people will be forced to relieve themselves outdoors, therefore public toilets are helpful in the areas of environmental health and human protection. It can be concluded that the provision of public toilet complexes at public places is important for community health, hygiene and sanitation.

The need to control disease and pollution in large cities, the desire to create beautiful, hygienic city forms the impetus to build good toilet (Greed, 2005). Statutorily, the 1936 Public Health Act (Section 87) gives local authorities the power to provide public toilets (McDermott and Kemohan, N.D). In 
addition, BSI BS6465 Part 1 (2006), section 7.4, states that 'the provision of sanitary appliances in public toilets should be determined according to local need'. Unfortunately, this good will and discretion to meet the public's needs is weighed in the balance against other local demands. The provision of public toilets is important for several reasons: people need to be able to access toilets when away from home; their closure, lack of availability or generally poor standards can be a cause for concern among would-be users. Also, a feeling from the people a lack of dignity and poor hygiene as they may have to resort to street fouling and the potential for spreading infection (Central Cities Institute, 2002). Public toilets can contribute to local economies if well planned, designed, maintained, clearly signposted and accessible. In Nigeria, unlike a country like Japan, there is little strategic planning for the provision of public toilets, even though they are vital parts of the city life.

Accordingly, the World Health Organization (WHO) in the fact sheet on "Sanitation in public places" states that toilets should be provided on the bus and railway stations (Drewko, 2007). In addition, the WHO guidelines suggest the presence of a staff to clean the toilets and supply toilet paper, soap and clean water. Markets where food is handled and eaten by a large number of people are expected to be provided with toilet facilities. In such markets, toilet facilities reduces the spread of infectious diseases such as cholera and diarrhoea. Schools are expected to be provided with sanitation facilities that are sufficient for staff and students, normally one toilet cubicle to 25 users is sufficient. They are to be equipped with hand washing basins, soap and water.

The opinion of users and their attitude towards public toilets is important. This is because it determines their willingness to use, and ability to pay-and-use them. In the face of people living on less than a dollar per day, the willingness tilts to spend money on food or clothing rather than paying for excreting. This study took place in Akure a highly urbanized settlement located in southwestern Nigeria. The objective of this study is to assess the present state of public toilets in Akure, Nigeria

\section{Materials ANd Methods}

The study area is Akure, located on latitude $7^{\circ} 15^{\prime}$ north and longitude $5^{\circ} 14^{\prime}$ east ofthe Greenwich Meridian. It occupies about $35 \mathrm{~km}^{2}$ of land and it is about $700 \mathrm{~km}$ Southwest of Abuja, the federal capital of Nigeria. Akure was originally the headquarters of the Ondo province until $3^{\text {rd }}$ February, 1976 when its status changed to the Capital of Ondo State, Nigeria. This led to a phenomena change in the political, social, economic and administrative roles as well as the population of the town. In the 2006 National Population Census exercise, the population of Akure was about 200, 000 persons. Akure is a traditional Nigerian city and, like other traditional Yoruba towns in the country, it existed long before the advent of British colonial rule in Nigeria. In determining the sample size, a total number of 20 households living within 200 metres to a public toilet take into consideration. In addition, people on transit, which include hawkers, travellers, and passersby was interviewed. Since it is difficult to get the sample frame for people on transit, purposive sampling technique was used in selecting 100 respondents for the study. The instruments for data collection were a set of questionnaires, digital camera and global positioning system (GPS). The questionnaire was administered and collected on the spot. The respondents were assisted by five 500 level students of the Federal University of Technology, Akure. They were trained in the administration of the questionnaire and its translation to Yoruba in case the respondent was an illiterate. In order to carry out a comprehensive survey, the sanitary section of Akure South Local Government area was contacted. At the Secretariat of the local government, a research assistant was appointed to aid the researcher in locating the public toilets. The Global positioning System (GPS) was used to capture the coordinates of the public toilets during the survey. These coordinates were thereafter plotted on the digitized Google earth map.

\section{RESULTS AND DISCUSSION}

\subsection{Location of Public Toilets}

There are a total of 11 public toilets (PTs) where money is collected and is accessible to the public in Akure (as revealed in Figure 1). Some of these facilities are located within the Central Business District (CBD) of the city. Most of these PTs were constructed by the World Bank, hence their concentration around places that are most trafficked by people, such as the Stadium, Central market, Oke-Ijebu Primary School and Akure High School area. However, it was discovered that facilities for the physically challenged was absent. In addition, most of the toilets were not signposted. At present, most PTs in Akure have not beenvandalized, with adequate privacy, varieties of toilet facilities, water 
from a nearby hand-dug well, modern roof materials and good floors. The PTs are at present serving a population of about 400,000 , hence if a toilet is to serve about $25-30$ persons it can be inferred that they are not sufficient.

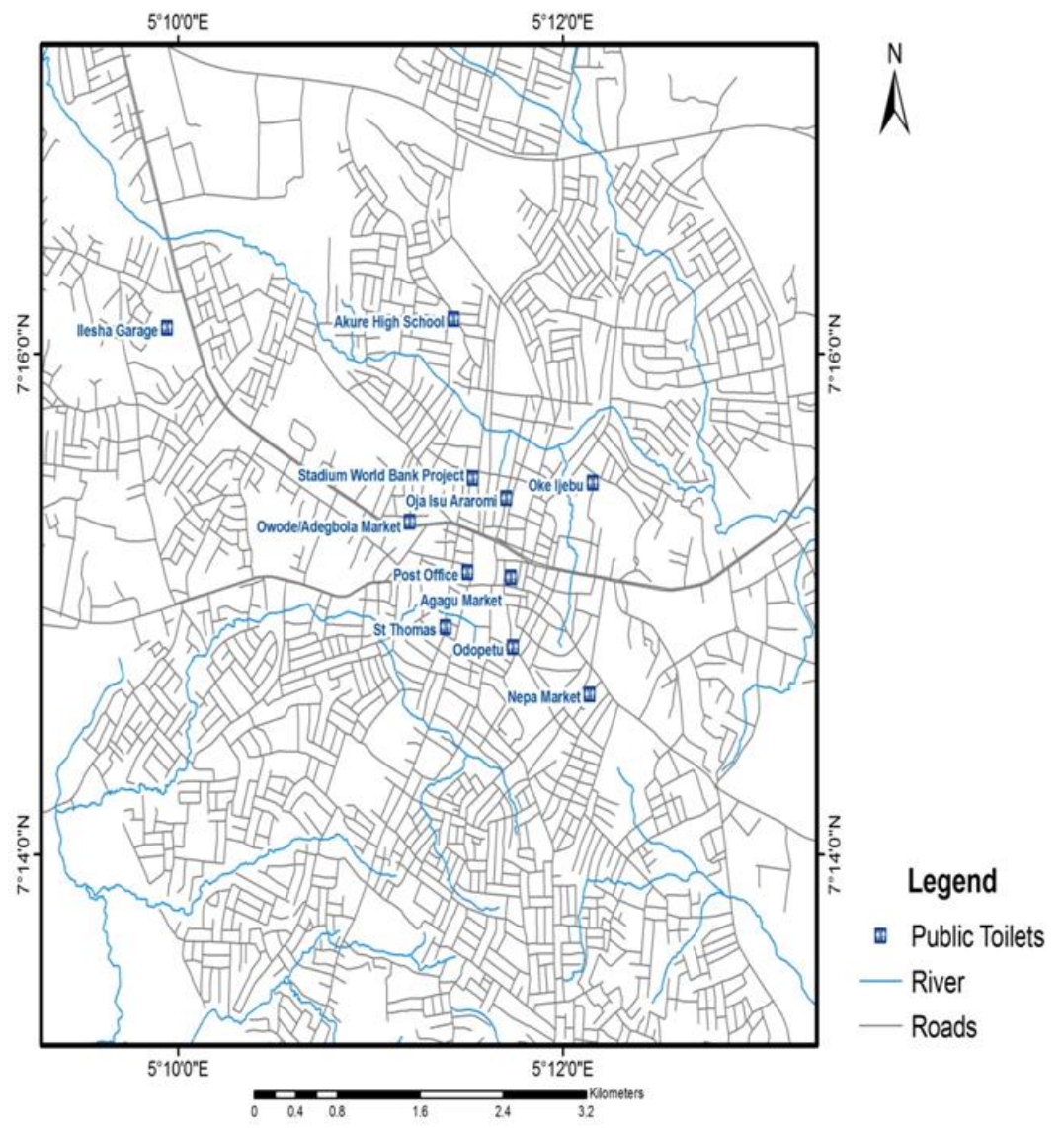

Figure1. Map Showing Public Toilet in Akure City

Source. Author's Fieldwork, 2017

\subsection{Distribution of Respondents by Gender}

Toilets in Akure were opened on week days from Monday to Friday except the ones located inside Oja-Oba market and Post office. The response rate to the questionnaire was satisfactory (100\%). Figure 2 shows that the majority of the respondents, $54 \%$ are male and $44 \%$ are female. The disparity reveals that more men use the public sanitation facilities than women. Having to defecate openly infringes on human safety and dignity. Availability of public toilet is useful to both sexes and more for women. This is for privacy and protection from the shame of having to defecate in public, or after painfully holding their bladder and bowels all day - risk attack by waiting until night falls.

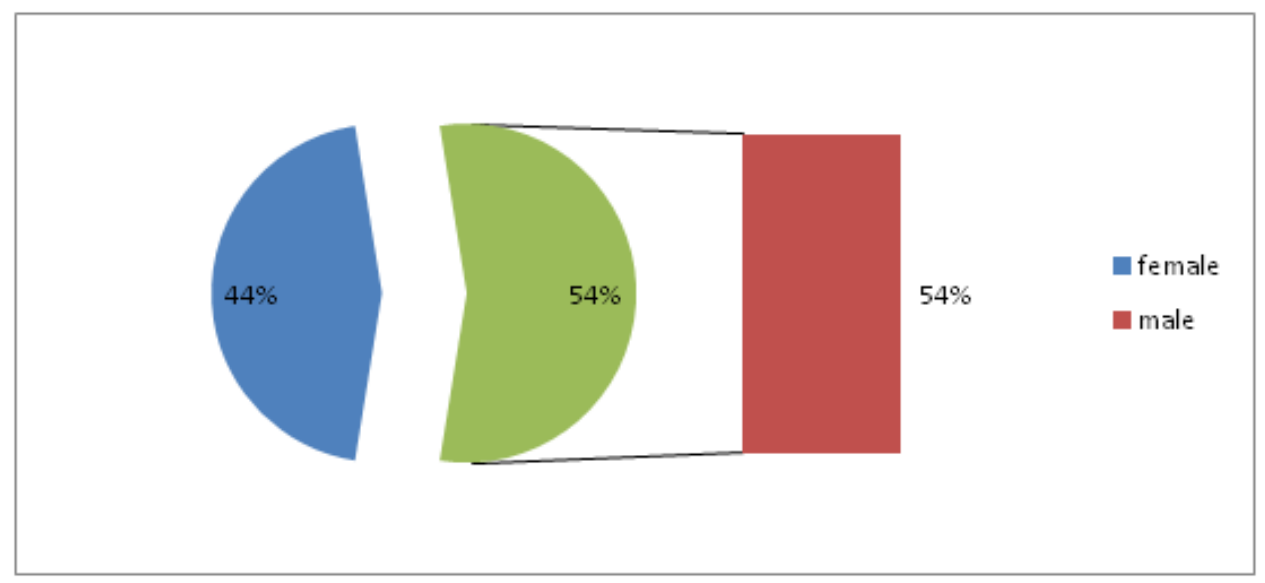

Figure2. Sex of Respondent

Source. Author's Fieldwork, 2017 


\subsection{Marital Status of Respondents}

As displayed in Table 1, the highest proportion of respondents in the study area is married, accounting for (56\%) of the total population sampled. This was followed by singles with (37\%). It was observed that $3 \%$ of respondents are widowed and $(4 \%)$ were divorced. This can be as a result of early marriage which many people are engaged in.

Table1. Marital Status

\begin{tabular}{|c|c|c|}
\hline Marital Status & Frequency & Percent \\
\hline Single & 37 & 37.0 \\
\hline Married & 56 & 56.0 \\
\hline Divorce & 4 & 4.0 \\
\hline Widow/Widower & 3 & 3.0 \\
\hline Total & 100 & 100.0 \\
\hline
\end{tabular}

Source. Author's Fieldwork, 2017

\subsection{Age of Respondents}

The respondents were asked about their age as depicted in table 2. The proportion of respondents between the 26-35 years ages bracket, accounting for $45 \%$. Respondents above 18 years but below 25 years were $32 \%$. Respondents between the ages of 36-25 years were $16 \%$ of the total. Respondents using public toilets in Akure, while those who were above 45years were 7\%. It is shown here that people between 18 and 45 years are the highest users of public latrine facilities, because they are more mobile than other age groups. It is equally expected that they are civilized enough to know the effect of improper sanitation to achieve a proper health condition in the environment.

Table2. Age of Respondent

\begin{tabular}{|c|c|c|}
\hline Age & Frequency & Percent \\
\hline $18-25$ & 32 & 32.0 \\
\hline $26-35$ & 45 & 45.0 \\
\hline $36-45$ & 16 & 16.0 \\
\hline $46-65$ & 7 & 7.0 \\
\hline Total & 100 & 100.0 \\
\hline
\end{tabular}

Source. Author's Fieldwork, 2017

\subsection{Educational Status of the Respondents}

From Figure 3, it can be deduced that the illiteracy level is considerably low because virtually all the respondents has various degrees of educational exposure. For instance, 53\% of the respondents are primary school leavers while $26 \%$ of the respondents have the Senior Secondary School Certificate (SSCE). $13 \%$ of the respondents are NCE holders, while $8 \%$ have others degree like B. Sc (Bachelor of Science), HND (Higher National Diploma). This implies that they are university and polytechnic graduates. It was observed that the major patrons of public toilets at Akure High School, Akure Stadium, Yam market, Odiolowo were petty traders and Hausas, hence the low education of respondents. They use the toilet for normal excretion and ablution while preparing for prayers.

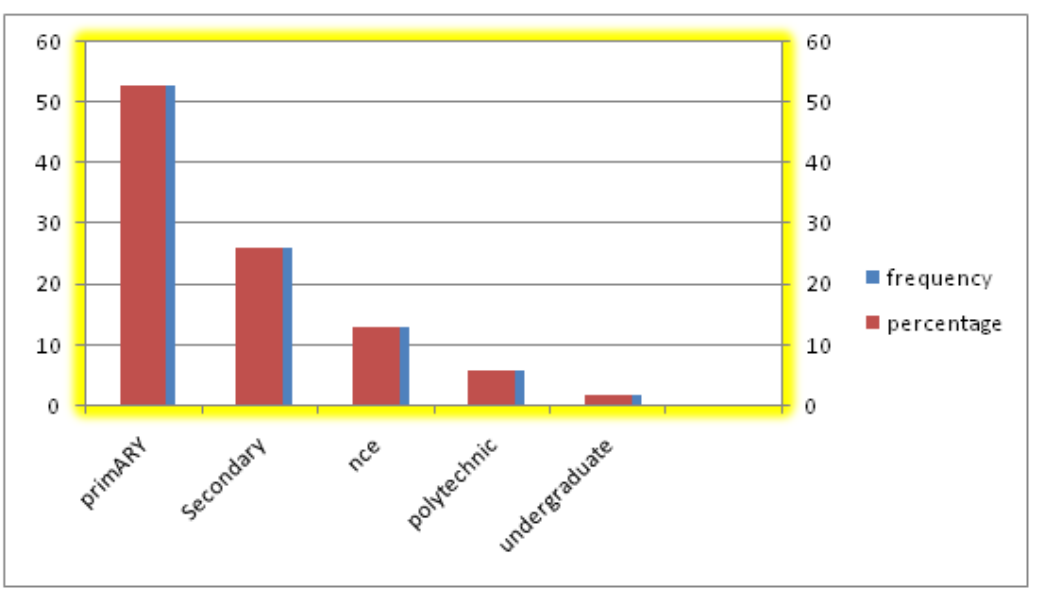

Figure3. Education status of Respondent

Source. Author's Fieldwork, 2017 


\subsection{Duration of stay of the Respondents}

Respondents were of the opinion that finding a public toilet while away from home. From their responses as depicted in table 3, it can be deduced that respondents to the research questionnaire have a different period of stay in each location of the public latrines accessed by the researcher. Respondents who has been staying in the area for less than 5years is $66 \%$ in the research. Residents who are between 6-10years respondent was $1 \%$, while the indigenous people who reside there for about 11-15years and are users of the latrine, though it constitute part of the respondent and has the total of $20 \%$, while $13 \%$ of respondent attest to the fact that they have been in the area for more than 16years.

Table3. Duration of stay of Respondent

\begin{tabular}{|c|c|c|}
\hline Duration & Frequency & Percent \\
\hline Less than 5years & 66 & 66.0 \\
\hline 6-10years & 1 & 1.0 \\
\hline 11-15years & 20 & 20.0 \\
\hline 16years and above & 13 & 13.0 \\
\hline Total & 100 & 100.0 \\
\hline
\end{tabular}

Source. Author's Fieldwork, 2017

\subsection{Acceptance of the Price for the use of Public Latrines}

At present the public toilets operate 'pay to pee' method where users were charged a token of Twenty naira. The Figure 4 shows the level of acceptance of people to the amount to be paid for the use of public latrines in the area. It reveals that $79 \%$ of the sampled populations are satisfied with the amount they pay, while $21 \%$ are not satisfied with the price. This is because they believe that it should be freely catered for by the government. It implies that in each and every location of the latrines, users are convenient with the use and price paid for the use of the latrines.

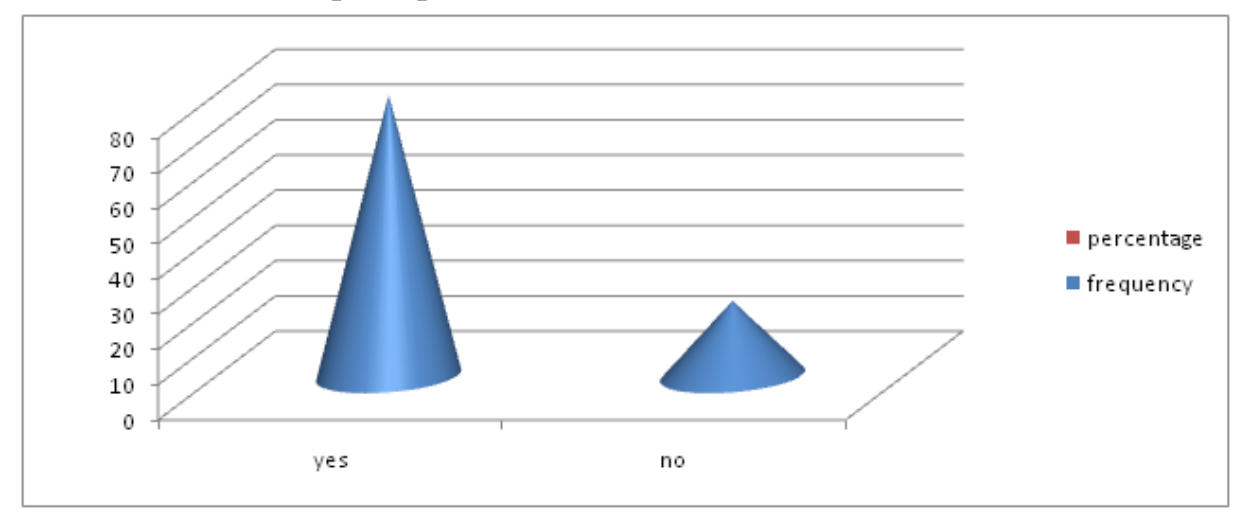

Figure4. Assessment on satisfaction with the price for the use of Public latrines

Source. Author's Fieldwork, 2017

\subsection{Frequency of using Public Latrines}

Table 4 shows that public latrines users visit the latrines daily and it serves as the easiest sanitation aids for them. The table shows that $73 \%$ of the respondents are good and frequent users of the public latrines. $25 \%$ of the respondent make use of the latrines not frequently, but sometimes once a week or few days in a week, while respondents that use the public latrine one in a month or yearly were $1 \%$ respectively. It was discovered that apart from the people on the move, the majority of the patrons of PTs were either resident in the areas, traders who spend most of the day in their shops or customers that came to buy goods in the markets.

Table4. Frequency of using Public latrines

\begin{tabular}{|c|c|c|}
\hline Frequency of use & Frequency & Percent \\
\hline Sometimes daily & 73 & 73.0 \\
\hline Few days per weekly & 25 & 25.0 \\
\hline Monthly basis & 1 & 1.0 \\
\hline Per year & 1 & 1.0 \\
\hline Total & 100 & 100.0 \\
\hline
\end{tabular}

Source. Author's Fieldwork, 2017 


\subsection{Conditions of the Public Latrines}

The respondents were asked to assess the various conditions of the public latrines in Akure. Overall, $60 \%$ of the respondent attests to the fact that the public latrines are being operated in a clean environment see figure 5. Various facilities of the latrines have been put into a clean state to protect the health of various users. $19 \%$ of respondent are of the opinion that the latrines had an environment that is in fair condition, $13 \%$ respondent attested that the condition of the latrines is good. While $6 \%$ adduced to high rate of privacy, $2 \%$ of the respondent view the conditions of the available facilities as poor.

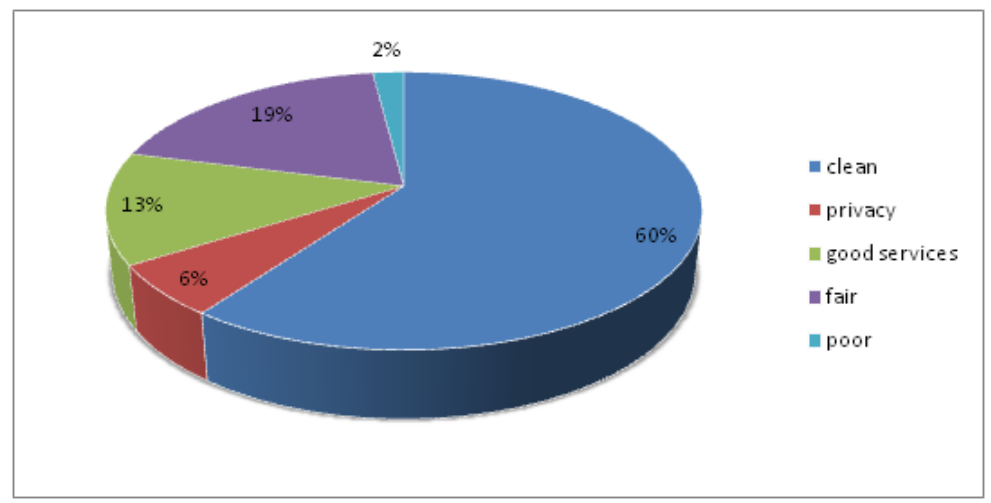

Figure5. Assessment of the conditions of the public latrines

Source. Author's Fieldwork, 2017

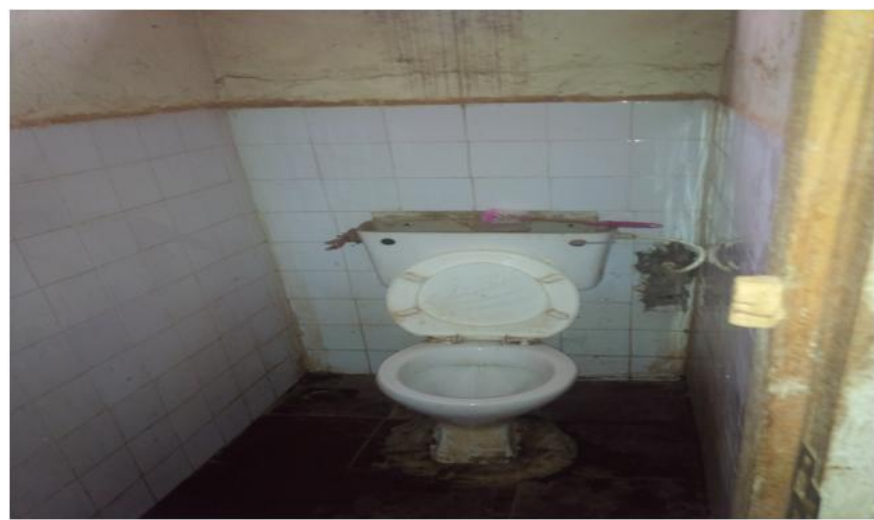

Figure6. The condition of public latrine at Post Office Akure, Ondo state

\subsection{Walking Distance to the Location of Public Latrines}

Figure 7 shows the walking distance of various latrine users from their place of activities and various household to the location of the latrines which they use. Seventy Eight percent of the respondents specified that they walk for about 5minutes to the location of the latrines. $18 \%$ show that the walking distance is between 5-10 minutes. 3\% of the users walk from a distance of about 10-20minutes walking distance. This implies that the latrines are located within short distances to most people patronizing them.

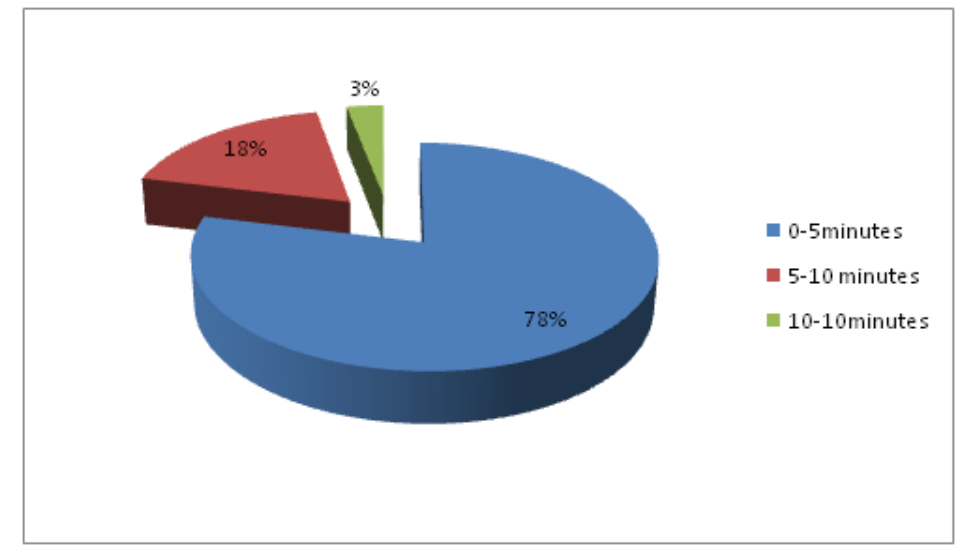

Figure7. The walking distances to latrines location 
Source. Author's Fieldwork, 2015

Using the recommended indicators for public latrine design, various urinals at the latrines was assessed and rated. Figure 8 revealed that most of the free urinals in the latrines are of poor sanitary quality and only a few of the urinals are of fairly good quality. More than $70 \%$ of the respondent said the urinals are of worse quality while less than $30 \%$ of the respondents said the urinals are of fairly poor quality while $7 \%$ of the urinals are fairly adequate. It implies that there is inadequate of urinals in the public latrines which causes one or two disability to the use of public latrines in the various locations.

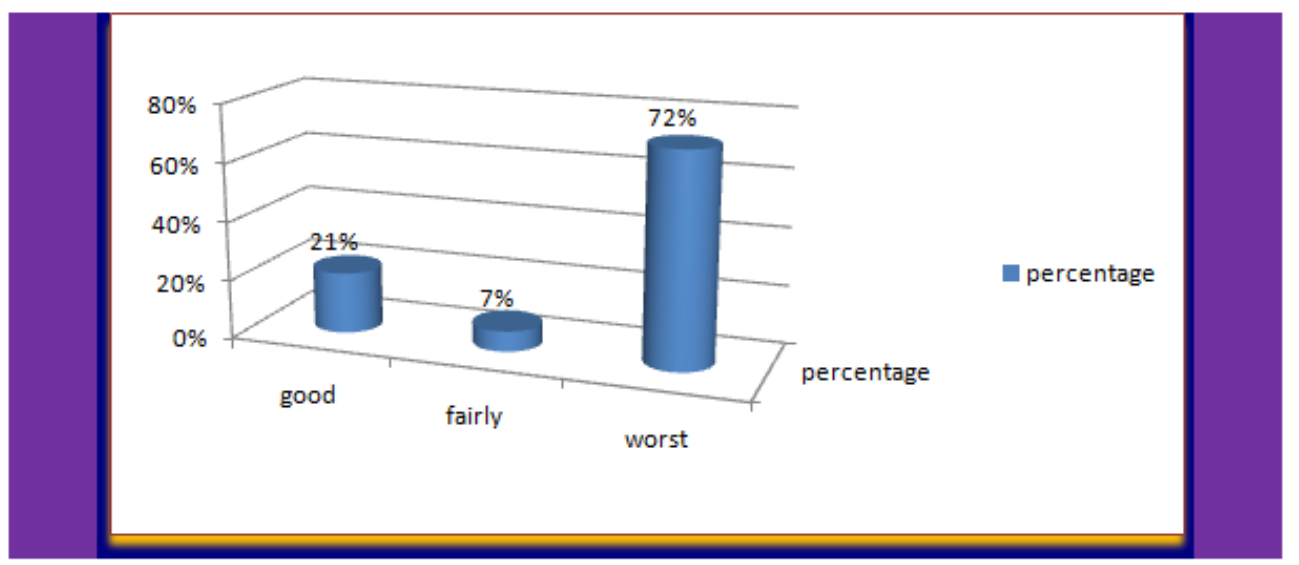

Figure8. Assessment on free urinals at the public latrines buildings

Source. Author's Fieldwork, 2015

\subsection{Problems Encountered while using Public Latrines}

The World Bank recognizes that lack of adequate public latrine facilities is one of the key constraints to short- and medium term sanitation crisis in Africa, and has thus been a major force in private and public latrine design and which gave rise to different problem in the use of available latrine systems in human environment. Findings as revealed in Figure 5 indicated that $22 \%$ of the respondent encountered the problem of dirtiness of toilets, while human waste and excreta were found in the early hours of the day because PT attendants close for work by 4:00 pm daily and were yet to resume. In addition, the attendants were not available during weekends and holidays.

The opinion of $27 \%$ was that the latrines were not well managed in terms of good rapport from attendantsto users, $46 \%$ of the respondent indicated that the majority of the latrines are not always available to users at peak period. This is a major challenge facing users of the public latrines. 5\% of respondent submitted that the only problem being faced with the use of the latrines is water shortage.

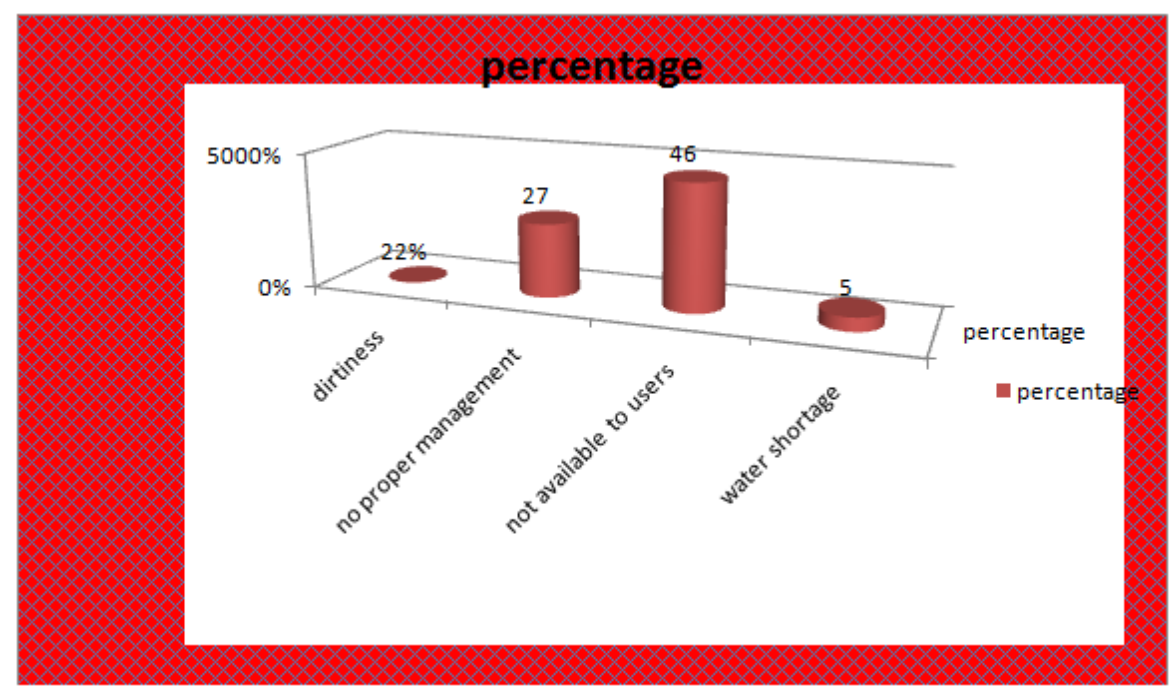

Figure9. Problems encountered while using the public latrines

Source. Author's Fieldwork, 2015 


\subsection{Other Services Rendered to Public Latrine Users}

It was revealed from the study as presented in table 5.The different services offered to users of the latrines. About $6 \%$ of respondents affirm that the available well- water aids them in cleaning their body after defecating. $20 \%$ confirm that sometimes the latrines caretaker offers them anal cleansing materials like tissue papers. Another $12 \%$ of respondent submit that soap was available to clean their hands after each use. $10 \%$ reveal that towels and other toilet materials such as brushes for washing the toilet were available.

Table5. Assessment on the type of services offered to users

\begin{tabular}{|c|c|c|}
\hline Service offered & Frequency & Percent \\
\hline Anal cleansing materials & 20 & 20.0 \\
\hline Water & 61 & 61.0 \\
\hline Soap & 12 & 12.0 \\
\hline Towels & 2 & 2.0 \\
\hline Other & 5 & 5.0 \\
\hline Total & 100 & 100.0 \\
\hline
\end{tabular}

Source. Author's Fieldwork, 2015

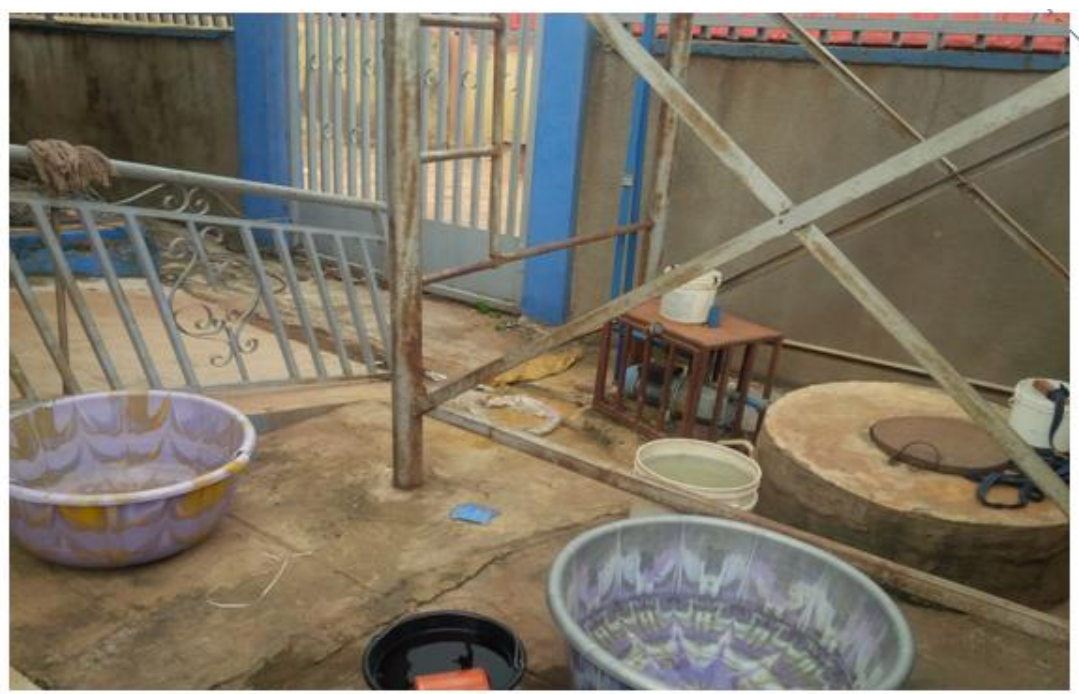

Figure10. Available water supply for public latrine users in Akure

\section{CONCLUSIONS AND RECOMMENDATION}

The study has brought into focus the issues of public latrines in Akure, Nigeria. It was discovered that initially, public latrine facilities were non-existent in Akure, Ondo state, a reprieve came due to direct construction of a public toilet by the World Bank, which had reduced the high rate of sanitation crisis affecting the health and living condition of various households.

The study identified that there is a limited number of assisted public latrine project in the study area which all offer services based on payment by users. People resident around various locations of the Latrine depend on public toilets as a means of defecating. Most people who do not reside but work in the area equally patronizes PTs. This is because they are left with no choice than to use them. The study further revealed that the major problems facing public conveniences are cleaned. Other shortcomings include Odour, dislodging, dirty sites and inadequacy of water, soap and towels. In addition, low staff morale is observed at the PT locations. Related to this is inadequate supervision and quality control,

Furthermore, some sites are overused, and do not have enough urinals and caretakers are not always available to open the toilet as at when necessary. This is as a result of inadequate sanitary workers to attend to users per day and this made most users to be dissatisfied with the services. The research reveals that only few patrons are very satisfied with the public latrines at the moment. This low level of satisfaction must be addressed and taken care of. Almost all the actors involved in the management of public latrines in the study area agreed that there is the need for effectiveness, quality of service, and improving standard according to user satisfaction. 
Users of World Bank assisted public toilets in Akure highly appreciated the availability of the facility. Many affirmed that it had saved them from the horrible experience of openly defecating while away from home. The most important aspect of the programme is that given the finances, it can be expanded to other places. The scheme symbolizes low-cost package of caring for people travelling and residents who were without toilet facilities at home. It holds the future for a salubrious environment without open defecation. It is recommended that all Motor parks, markets and schools in the metropolis should be served.

\section{REFERENCES}

[1] Drewko, A. (2007). "Resource-Oriented Public Toilets in Developing Countries: Ideas, Design, Operation and Maintenance for Arba Minch, Ethiopia". PhD Thesis. Technische Universitat. Hamburgh-Harbug, Germany.

[2] Niwagba C. (2007). Human Excreta Treatment Technologies - prerequisites, constraints and Performance. $\mathrm{PhD}$ Thesis. Department of Biometry and Engineering, Swedish University of Agricultural Sciences ISSN 1652-3261.

[3] NPC (1996) National Population Census, Nigeria.

[4] ODSG (2010): report of the statistical survey Ondo state. Conducted by research and statistic department, ministry of economic planning and budgeting, Akure.

[5] Ondo State of Nigeria, (1990). Report of the statistical survey Ondo state. Conducted by national census 1990.

[6] Okoko E. (2001), quantitative techniques in urban analysis, Ibadan. Kraft books

[7] Pathak, B. (1991). Maintenance Management of Public Toilets: Experience of a Non-Government Organization. Building and Environment. 26(3)313-315.

[8] WHO (2004). Water, Sanitation and Hygiene Links to Health. Facts and Figures updated November 2004. Also available at: http://www.who.int/water_sanitation_health/publication/facts2004en/en/. Accessed on $22^{\text {nd }}$ June 2015.

Citation: Dr. Olukayode Rotowa, " Assessment of Public Lavatories in Akure, Nigeria", International Journal of Research in Environmental Science (IJRES), vol. 6, no.1, pp. 10-18, 2020. Available: DOI: http://dx.doi.org/ 10.20431/2454-9444.0601002

Copyright: () 2020 Authors. This is an open-access article distributed under the terms of the Creative Commons Attribution License, which permits unrestricted use, distribution, and reproduction in any medium, provided the original author and source are credited. 